\title{
SGLT2 inhibitors - an insulin-independent therapeutic approach for treatment of type 2 diabetes: focus on canagliflozin
}

This article was published in the following Dove Press journal:

Diabetes, Metabolic Syndrome and Obesity: Targets and Therapy

9 November 2015

Number of times this article has been viewed

\section{Jochen Seufert}

Department of Endocrinology and Diabetology, Clinic for Internal Medicine II, Freiburg University Hospital, Freiburg, Germany
Correspondence: Jochen Seufert Department of Endocrinology and Diabetology, Clinic for Internal Medicine II, Freiburg University Hospital, Hugstetter Str. 55, 79106 Freiburg/Breisgau, Germany Tel +4976127034200 Fax +4976I 27034130 Email jochen.seufert@uniklinik-freiburg.de
Abstract: Despite the availability of a great variety of medications, a significant proportion of people with type 2 diabetes mellitus (T2DM) are not able to achieve or maintain adequate glycemic control. Beyond improved glucose control, novel treatments would ideally provide a reduction of cardiovascular risk, with a favorable impact on excess weight, and a low intrinsic hypoglycemia risk, as well as a synergistic mechanism of action for broad combination therapy. With the development of sodium glucose cotransporter 2 (SGLT2) inhibitors, an antidiabetic pharmacologic option has recently become available that comes close to meeting these requirements. For the first time, SGLT2 inhibitors offer a therapeutic approach acting directly on the kidneys without requiring insulin secretion or action. Canagliflozin, dapagliflozin, and empagliflozin are the SGLT2 inhibitors approved to date. Taken once a day, these medications can be combined with all other antidiabetic medications including insulin, due to their insulinindependent mechanism of action, with only a minimal risk of hypoglycemia. SGLT2 inhibitors provide additional reductions in body weight and blood pressure due to the therapeutically induced excretion of glucose and sodium through the kidneys. These "concomitant effects" are particularly interesting with regard to the increased cardiovascular risk in T2DM. In many cases, T2DM treatment requires a multidimensional approach where the treatment goals have to be adapted to the individual patient. While there is a consensus on the use of metformin as a firstline drug therapy, various antidiabetics are used for treatment intensification. New mechanisms of action like that of SGLT2 inhibitors such as canagliflozin, which can be used both in early and late stages of diabetes, are a welcome addition to expand the treatment options for patients at every stage of T2DM. The efficacy and tolerability of canagliflozin have been tested in an extensive clinical trial program described in this review article.

Keywords: sodium glucose cotransporter 2 (SGLT2) inhibitor, canagliflozin, dapagliflozin, empagliflozin, type 2 diabetes

\section{Why do we need new antidiabetics?}

Although a range of therapeutic options are available for the treatment of type 2 diabetes mellitus (T2DM), ${ }^{1}$ disease progression still remains a challenge. Nearly $40 \%$ of patients with T2DM in Europe do not achieve $\mathrm{HbA}_{1 \mathrm{c}}$ targets at a level of $<7.0 \%{ }^{2}$ Moreover, glycemic control continues to worsen over the course of the disease for a variety of reasons, such as fading endogenous insulin secretion and clinical inertia to counteract this pathophysiology by adequate intensification of medical therapy. ${ }^{3}$

A central aspect of T2DM is the development of chronic complications associated with high morbidity and mortality. ${ }^{4}$ In addition to microvascular complications at the retina and kidneys, in particular, the risk of developing cardiovascular events, such as myocardial infarction, stroke, and peripheral artery disease, is life-threatening. 
On average, patients with T2DM have an approximately two-fold higher risk of vascular diseases, such as coronary heart disease and ischemic strokes, ${ }^{5}$ compared to people without diabetes of the same age. The German Metabolic and Cardiovascular Risk Project has screened patients nationwide from general practitioner practices and observed that $43 \%$ of male and $35 \%$ of female patients with T2DM have experienced at least one cardiovascular event (eg, heart attack, acute coronary syndrome, stroke, transient ischemic attack, peripheral arterial occlusive disease, and/ or heart failure). In comparison, a corresponding diagnosis existed for only $16.4 \%$ of male and $8.8 \%$ of female patients without diabetes. ${ }^{6}$ The DUTY register in Germany shows that, in many cases, the targets for cardiovascular risk factors are not achieved by patients with T2DM. Despite established antihypertensive treatment, approximately $65 \%$ of patients display $>140 \mathrm{mmHg}$ systolic or $>90 \mathrm{mmHg}$ diastolic blood pressure levels. ${ }^{7}$ More than $80 \%$ of people with T2DM are overweight or obese. ${ }^{7}$ Lipid-lowering agents are used in approximately one-third of cases, but more than one-quarter of patients do not achieve target levels for low-density lipoprotein cholesterol. ${ }^{7}$ Until now, there have been no results from controlled studies with clinical endpoints that delivered conclusive evidence of macrovascular event reduction by an antidiabetic medication, except for 340 overweight patients treated by metformin in the UK Prospective Diabetes Study, ${ }^{8}$ and for the secondary cardiovascular endpoint in patients treated by pioglitazone in the PROactive trial. ${ }^{9}$ The recent cardiovascular endpoint studies SAVOR-TIMI 53 and EXAMINE, published in 2013, displayed a neutral effect on cardiovascular outcomes for the antidiabetic dipeptidyl peptidase-4 (DPP-4) inhibitors saxagliptin and alogliptin without being able to demonstrate any cardiovascular benefit. ${ }^{10,11}$

Currently, there is an evidence-based consensus that T2DM treatment should be more closely adapted to individual patient situations (ie, "individualization" of therapy). ${ }^{1,4}$ Among other things, patient preferences, age, comorbidities, and the risks of hypoglycemia and complications play an important role. ${ }^{4}$ The benefits and possible side effects of antidiabetic substances under consideration must also be weighed on an individual patient basis. Major considerations for the use of different antidiabetic medications include treatment-induced weight gain and hypoglycemia risk. ${ }^{4}$

With the sodium glucose cotransporter 2 (SGLT2) inhibitor class of drugs, a new pharmacologic option has been recently developed for oral antidiabetic treatment. Notably, SGLT2 inhibition offers an oral therapeutic approach that acts directly on the kidneys and is insulin-independent (ie, independent of pancreatic beta-cell function and/or existing insulin resistance; Figure 1). Currently licensed SGLT2 inhibitors comprise canagliflozin, dapagliflozin, and empagliflozin. Focusing on canagliflozin, the following overview presents the mechanism of action, the glycemic efficacy, pleiotropic concomitant effects on blood pressure and body weight, and the tolerability profile of this SGLT2 inhibitor, and discusses how canagliflozin can usefully expand the existing T2DM therapeutic arsenal in routine practice and what limitations need to be taken into account.

\section{The principle of SGLT2 inhibition}

The kidneys contribute substantially to the regulation of glucose homeostasis. Alongside gluconeogenesis, this contribution primarily involves glomerular filtration and tubular reabsorption of glucose. ${ }^{12}$ Glucose reabsorption specifically takes place in the proximal kidney tubules as an active transport mediated through SGLT2 (responsible for approximately $90 \%$ of reabsorption) and SGLT1 (responsible for approximately $10 \%$ of reabsorption). While the amounts of freely filtered glucose are positively correlated with the serum glucose concentrations, the reabsorption process of glucose through SGLTs represents a saturable mechanism. As a clinical consequence, exceeding the glucose transport capacity of SGLT functional proteins by an excess of filtered glucose during hyperglycemia leads to glucosuria. ${ }^{12}$

Paradoxically, it has been demonstrated that there is increased glucose reabsorption despite elevated serum glucose levels in patients with T2DM. This mechanism may very well contribute to the derangement of glucose homeostasis and further increase hyperglycemia. Mechanistically, in vitro investigations demonstrate that renal tubular cells from patients with T2DM express more SGLT2 proteins as compared with tubular cells from controls without T2DM. ${ }^{13}$ The enhanced glucose reabsorption and the consecutive increase in the serum glucose concentrations are therefore presumably explained by an overexpression or increased activity of SGLT proteins. ${ }^{13}$ SGLT2 inhibitors directly target this pathophysiologic dysregulation by inhibiting the transport protein function. As a consequence, the pathologically elevated kidney threshold for glucose is reduced, and the main therapeutic effect is exerted by excretion of excess glucose with the urine (ie, therapeutic glycosuria). In Phase I studies with the SGLT2 inhibitor canagliflozin, this lowering of the renal threshold for glucose $\left(\mathrm{RT}_{\mathrm{G}}\right)$ led to increased urine excretion of approximately $77-119 \mathrm{~g} / \mathrm{d}$. This can be translated into a calorie loss of $308-476 \mathrm{kcal} / \mathrm{d} .{ }^{14} \mathrm{~A}$ Phase I study in healthy 


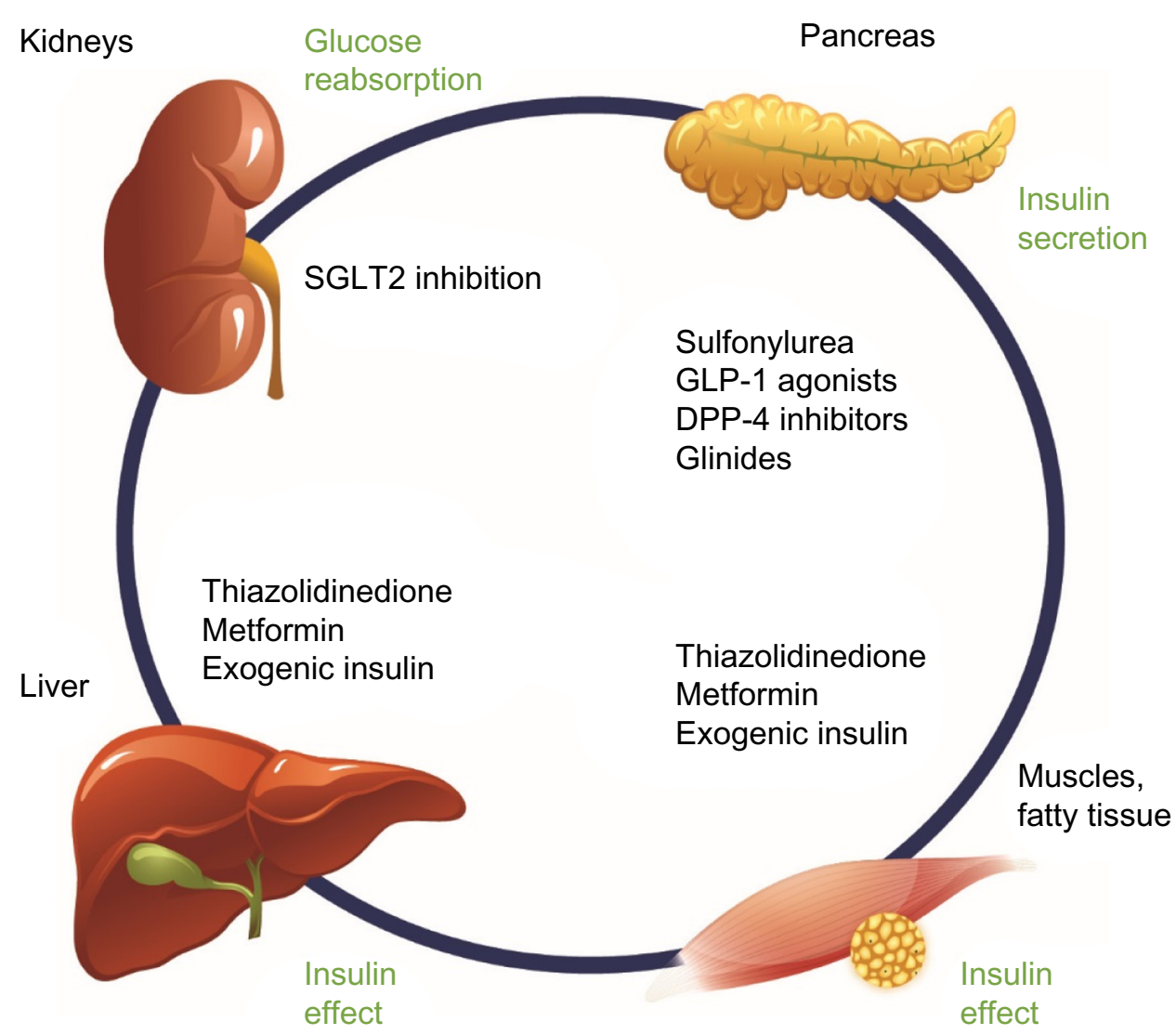

Figure I Pharmacologic options for the treatment of T2DM: SGLT2 inhibition in the kidneys complements existing treatment options through an insulin-independent mechanism of action.

Notes: Adapted from Seufert J. SGLT-2 inhibition with canagliflozin: a new option for the treatment of type 2 diabetes. Dtsch Med Wochenschr. 20I4;।39(Suppl 2): S52-S58. (C) Georg Thieme Verlag KG. ${ }^{21}$

Abbreviations: T2DM, type 2 diabetes mellitus; SGLT2, sodium glucose cotransporter 2; GLP-I, glucagon-like peptide- I; DPP-4, dipeptidyl peptidase-4.

participants showed that 24-hour urinary glucose excretion was approximately $25 \%$ higher with canagliflozin $300 \mathrm{mg}$ compared with dapagliflozin $10 \mathrm{mg} .{ }^{15}$ In Phase III studies, the use of canagliflozin $300 \mathrm{mg}$ was also associated with a reduction in postprandial glucose excursion, which may indicate an additional transient, partial inhibition of intestinal SGLT $1 .{ }^{16}$ In the Phase I study comparing canagliflozin with dapagliflozin, dapagliflozin $10 \mathrm{mg}$ did not have an effect on postprandial glucose excursion in healthy participants. ${ }^{15}$ In a separate study, empagliflozin had no effect on postprandial glucose excursion in patients with T2DM. ${ }^{17}$ A slight pharmacologic effect on SGLT1 has previously been demonstrated with canagliflozin in vitro. ${ }^{18}$ However, this seems to be a minor effect, as signs of carbohydrate malabsorption have not been observed with canagliflozin treatment. ${ }^{14}$

In patients with T2DM, SGLT2 inhibition causes an antihyperglycemic effect ${ }^{19}$ that, contrary to other antidiabetic substances, is neither directly nor indirectly dependent on the pancreatic beta-cell, insulin secretion, and/or insulin sensitivity (ie, represents a completely insulin-independent mechanism of action; Figure 1). ${ }^{20}$ Accordingly, SGLT2 inhibitors can be very well additively combined with other agents with different antihyperglycemic mechanisms of action.

\section{History of therapeutic SGLT2 inhibition}

SGLT2-inhibitor medications functionally imitate the clinical effect of a mutation in the SGLT2 gene that was discovered as the genetic basis for a rare monogenetic disease called familial hereditary renal glucosuria. Patients harboring these mutations lose glucose through the kidneys to different extents from early in life throughout the life span without experiencing any relevant morbidity or mortality related to this defect. In vivo investigations show that the pharmacologic intervention by SGLT2 inhibitors only inhibits up to $50 \%$ of the SGLT2 activity and, therefore, the magnitude of glucosuria is, in principle, lower than in many people with inactivating SGLT2 gene mutations. ${ }^{21}$ One of the first pharmacologically investigated substances for therapeutic SGLT2 inhibition was phlorizin, a plant-based glycoside of the 
flavonoid group..$^{22}$ Further development of phlorizin was later abandoned in favor of other substances, owing to low bioavailability and lack of specificity for SGLT2. Canagliflozin, dapagliflozin, and empagliflozin are SGLT2 inhibitors that have been approved for the treatment of adults with T2DM in the United States and Europe; consistent with their shared mechanism of action, these agents have been associated with improvements in glycemic control, weight loss, and blood pressure reductions in patients with T2DM. ${ }^{14,23,24}$ To date, there have not been any head-to-head clinical studies of these agents in patients with T2DM. Results from the canagliflozin clinical development program are detailed below.

\section{Phase III clinical trial program with the SGLT2 inhibitor canagliflozin}

A total of 10,285 patients with T2DM participated in the prospective, double-blind, controlled studies investigating the efficacy and safety of the SGLT2 inhibitor canagliflozin. ${ }^{14}$ Specific populations, such as elderly patients, patients with moderate renal impairment, and patients with cardiovascular disease or a high cardiovascular risk, were also included in the trial portfolio. The studies with canagliflozin investigate monotherapy as adjunct to diet and exercise, dual therapy with metformin or a sulfonylurea, triple therapy with metformin and a sulfonylurea or pioglitazone, and combination therapy with insulin (with or without additional oral antidiabetic substances; Figure 2) ${ }^{14}$ Furthermore, in addition to the pivotal Phase III trials, an extensive long-term clinical outcome study program (including the CANagliflozin cardioVascular Assessment
Study [CANVAS $]^{25}$ and CANVAS-R) was initiated to investigate the impact of canagliflozin on classical macrovascular and microvascular endpoints in patients with T2DM. One of the emphases is on renal parameters; the CANVAS-R study (ClinicalTrials.gov identifier, NCT01989754), which was initiated after license authorization, will test the effects of canagliflozin on the progression of albuminuria and the progression of diabetic nephropathy, for example. Reporting of the outcomes from these endpoint studies is expected in 2017. A recently initiated renal outcomes trial (Canagliflozin and Renal Events in Diabetes with Established Nephropathy Clinical Evaluation Trial [CREDENCE]; ClinicalTrials.gov identifier, NCT02065791) will assess the renal protective effect of canagliflozin in patients with T2DM, Stage 2 or 3 chronic kidney disease, and macroalbuminuria receiving standard of care and treatment with an angiotensin-converting enzyme inhibitor or angiotensin receptor blocker; this study is expected to be completed in 2019 .

\section{Efficacy of canagliflozin in glycemic control}

The Phase III trial program in patients with T2DM shows clinically relevant improvements in glycemic control for canagliflozin in both monotherapy and in combination with other antidiabetics (dual therapy, triple therapy, and in combination with insulin; Table 1$) ;{ }^{26-35}$ long-term data are available from individual clinical studies over treatment periods of up to 104 weeks. ${ }^{27-35}$ The results of the study program confirm the propensity of canagliflozin to combine well with

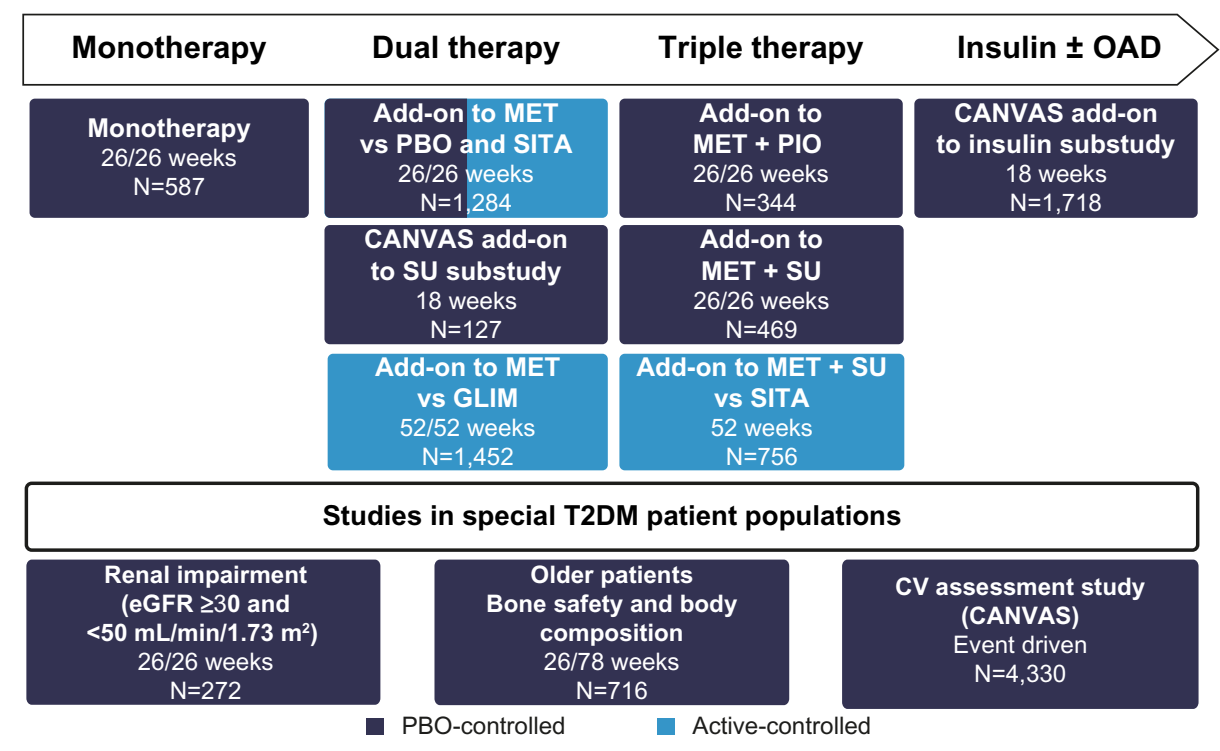

Figure 2 Phase III trial program with canagliflozin.

Notes: Data from published studies. ${ }^{14,26,28-32,34}$

Abbreviations: OAD, oral antidiabetic; MET, metformin; PBO, placebo; SITA, sitagliptin; PIO, pioglitazone; CANVAS, CANagliflozin cardioVascular Assessment Study; SU, sulfonylurea; GLIM, glimepiride; T2DM, type 2 diabetes mellitus; CV, cardiovascular; eGFR, estimated glomerular filtration rate. 


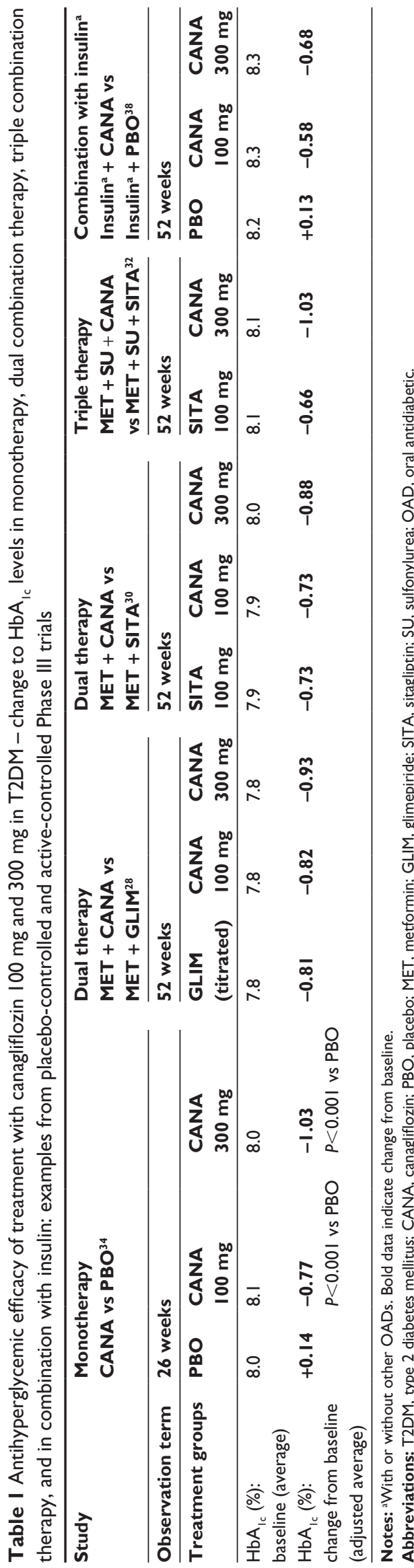

other agents with different, synergistic antihyperglycemic mechanisms of action, including exogenous insulin administration (Table 1). ${ }^{26-35}$

Based on its mode of action, the efficacy of SGLT2 inhibition depends on the magnitude of the glomerular filtration rate (GFR), and therefore less glucose lowering occurs in patients with impaired kidney function. ${ }^{14}$ This is because with reduced GFR, the glomerular filtration of glucose is lowered, which renders inhibition of glucose reabsorption through SGLT2 less effective. However, an analysis of six randomized, double-blind, Phase III studies revealed that canagliflozin considerably reduced $\mathrm{HbA}_{1 \mathrm{c}}$ levels compared with placebo also in mild-to-moderate kidney disease. In patients with an estimated glomerular filtration rate (eGFR) $\geq 60$ to $<90 \mathrm{~mL} / \mathrm{min} / 1.73 \mathrm{~m}^{2}$, average $\mathrm{HbA}_{1 \mathrm{c}}$ reductions of approximately $-0.63 \%$ and $-0.80 \%$ were achieved with canagliflozin $100 \mathrm{mg}$ and $300 \mathrm{mg}$, respectively; in patients with an eGFR $\geq 45$ to $<60 \mathrm{~mL} / \mathrm{min} / 1.73 \mathrm{~m}^{2}$, the $\mathrm{HbA}_{\mathrm{lc}}$ reductions were $-0.57 \%$ and $-0.61 \%$, respectively $\left(P<0.001\right.$ vs placebo). ${ }^{36}$ According to the label, in patients with an eGFR $\geq 45$ to $<60 \mathrm{~mL} / \mathrm{min} / 1.73 \mathrm{~m}^{2}$, the dose of canagliflozin should be adjusted to $100 \mathrm{mg}$ once a day. ${ }^{14}$

Canagliflozin is the only licensed SGLT2 inhibitor to demonstrate superiority in $\mathrm{HbA}_{1 \mathrm{c}}$ reduction as compared with the DPP-4 inhibitor sitagliptin and the sulfonylurea glimepiride. A total of three 52-week studies compared canagliflozin directly with sitagliptin (in dual and triple therapy), ${ }^{30,32}$ and with glimepiride (in dual therapy). ${ }^{28}$ In these studies, canagliflozin $300 \mathrm{mg}$ showed statistically superior reductions of $\mathrm{HbA}_{1 \mathrm{c}}$ as compared with both sitagliptin and glimepiride..$^{14,28,30,32}$ In the study versus glimepiride (in dual therapy with metformin), stable $\mathrm{HbA}_{1 \mathrm{c}}$ reductions with canagliflozin were maintained over a long-term treatment period of 104 weeks. ${ }^{27}$

\section{Direct comparison between canagliflozin and sitagliptin}

The efficacy and tolerability of canagliflozin as add-on to metformin were directly compared with the DPP-4 inhibitor sitagliptin $100 \mathrm{mg}$ in a 52-week study. ${ }^{30}$ The results showed that canagliflozin $100 \mathrm{mg}$ was noninferior to sitagliptin in $\mathrm{HbA}_{1 \mathrm{c}}$ reduction, and canagliflozin $300 \mathrm{mg}$ was statistically superior (Table 1). Beyond the effect on blood glucose control, canagliflozin treatment was associated with weight loss and systolic blood pressure reductions for both tested doses of canagliflozin (100 mg and $300 \mathrm{mg}$ ). Again, the differences were statistically significant compared with sitagliptin (Figures 3 and 4). 


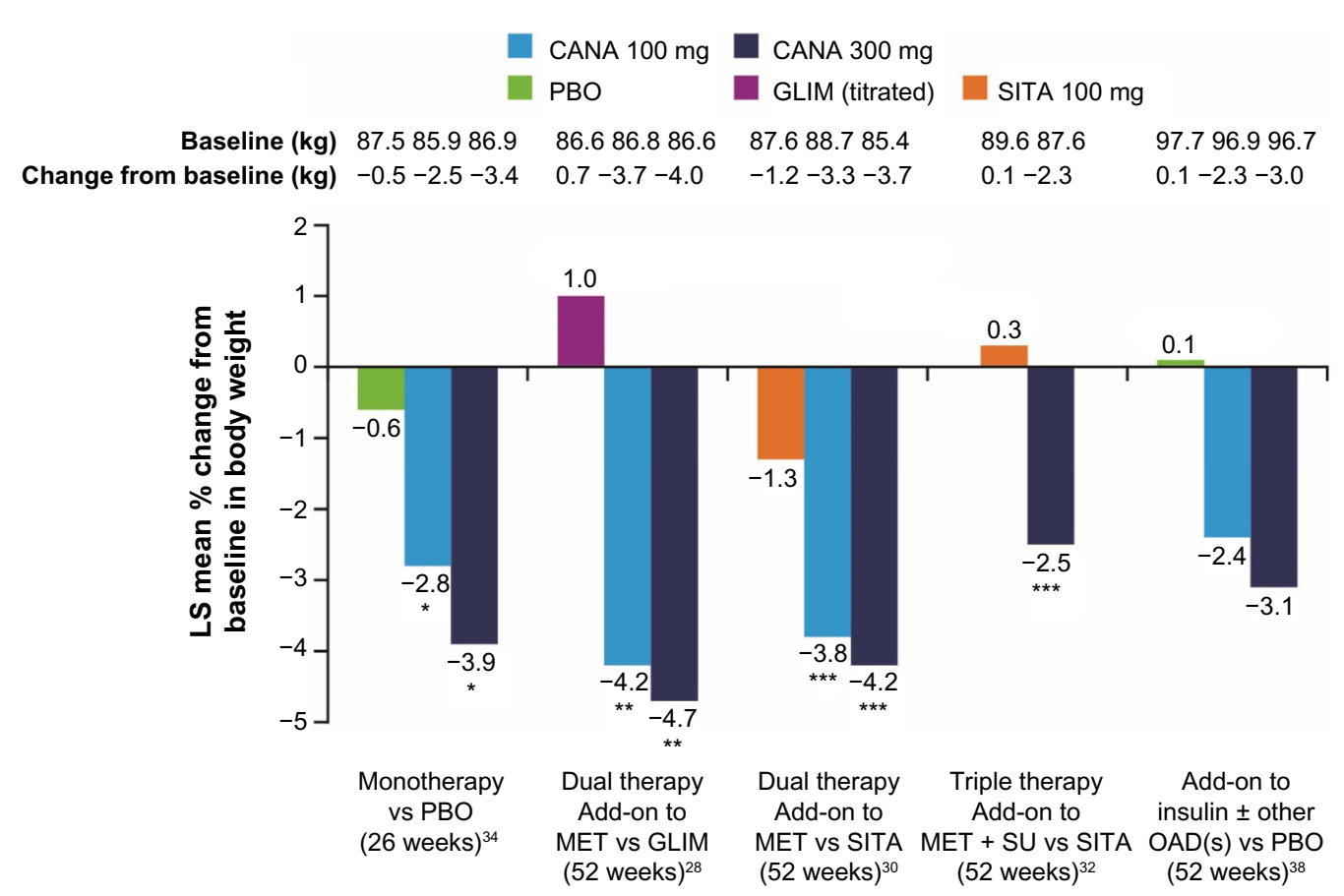

Figure 3 Percent change in body weight as a concomitant effect of SGLT2 inhibition with canagliflozin $100 \mathrm{mg}$ and $300 \mathrm{mg}$ in a direct comparison with placebo, glimepiride, and sitagliptin: examples from clinical Phase III trials on canagliflozin monotherapy, dual combination therapy, triple combination therapy, and in combination with insulin. Notes: $* P<0.001$ vs PBO. $* * P<0.0001$ vs GLIM. $* * * P<0.001$ vs SITA.

Abbreviations: SGLT2, sodium glucose cotransporter 2; CANA, canagliflozin; PBO, placebo; GLIM, glimepiride; SITA, sitagliptin; LS, least squares; MET, metformin; $\mathrm{SU}$, sulfonylurea; OAD, oral antidiabetic.

CANA $100 \mathrm{mg}$
PBO CANA $300 \mathrm{mg}$
GLIM (titrated) $\quad$ SITA $100 \mathrm{mg}$

Baseline (mmHg) $127.7126 .7128 .5 \quad 129.5130 .0130 .0 \quad 128.0128 .0128 .7 \quad 130.1131 .2 \quad 138.2137 .0138 .2$

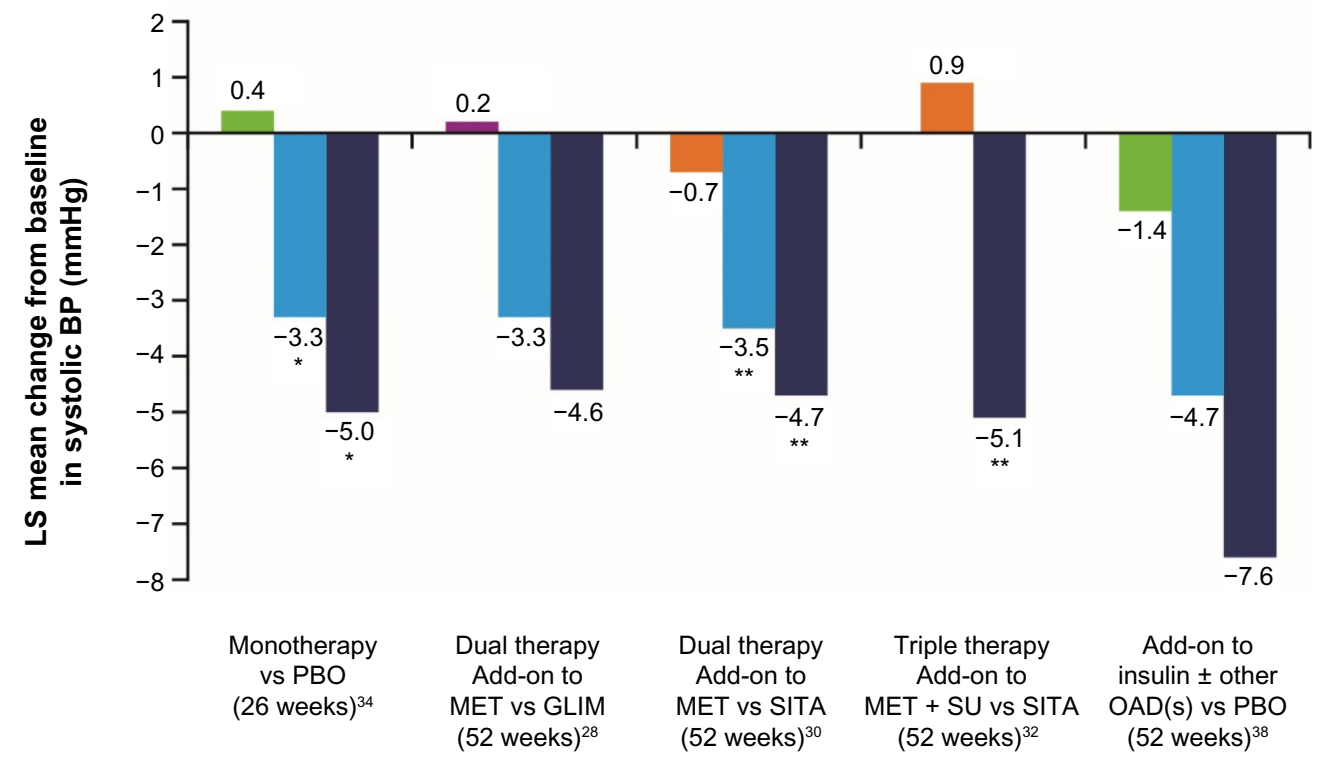

Figure 4 Changes to systolic blood pressure levels as a concomitant effect of SGLT2 inhibition with canagliflozin $100 \mathrm{mg}$ and $300 \mathrm{mg}$ in a direct comparison with placebo, glimepiride, and sitagliptin: examples from clinical Phase III trials with canagliflozin monotherapy, dual combination therapy, triple combination therapy, and in combination with insulin.

Notes: $* P<0.001$ vs PBO. $* * P<0.001$ vs SITA.

Abbreviations: SGLT2, sodium glucose cotransporter 2; CANA, canagliflozin; PBO, placebo; GLIM, glimepiride; SITA, sitagliptin; LS, least squares; BP, blood pressure; MET, metformin; SU, sulfonylurea; OAD, oral antidiabetic. 
A 52-week study of canagliflozin in triple combination treatment with metformin and sulfonylurea demonstrated similar results for patients with T2DM when compared with the triple combination regime of metformin, sulfonylurea, and sitagliptin. ${ }^{32}$ Canagliflozin $300 \mathrm{mg}$ achieved more effective glycemic control as compared with the DPP-4 inhibitor sitagliptin-containing regimen (Table 1). The blood glucose-lowering effect of canagliflozin was again associated with significant weight loss and reductions of systolic blood pressure (Figures 3 and 4).

\section{Direct comparison between canagliflozin and glimepiride}

A further 52-week study compared canagliflozin with the sulfonylurea glimepiride as add-on to stable metformin treatment. ${ }^{28} \mathrm{After} 52$ weeks, $\mathrm{HbA}_{1 \mathrm{c}}$ reduction by canagliflozin $100 \mathrm{mg}$ was shown to be noninferior to the sulfonylurea glimepiride (average dose: $5.6 \mathrm{mg}$ ), and canagliflozin $300 \mathrm{mg}$ was statistically superior (Table 1). With glimepiride, a gradual slight increase in $\mathrm{HbA}_{1 \mathrm{c}}$ levels was observed after week 18 , although the sulfonylurea dose could be titrated up over the course of the entire 52-week treatment period.

In addition to better glycemic control, again canagliflozin significantly reduced body weight with both doses compared to glimepiride, which showed a tendency to increase weight (Figure 3). Furthermore, canagliflozin also led to reductions in systolic blood pressure (Figure 4). Documented hypoglycemia was significantly less frequent with canagliflozin $100 \mathrm{mg}$ and $300 \mathrm{mg}$ ( $6 \%$ and 5\%, respectively) compared with glimepiride (34\%), in spite of a more prominent long-term effect on $\mathrm{HbA}_{1 \mathrm{c}}$ reduction with canagliflozin $300 \mathrm{mg}$.

\section{Concomitant effects on body weight}

The mechanism of action of SGLT2 inhibition induces a therapeutic increase in glucose excretion through urine (77-119 g/d with canagliflozin $100 \mathrm{mg}$ or $300 \mathrm{mg}$ ), which represents a substantial calorie loss that amounts to 308-476 kcal daily with canagliflozin $100 \mathrm{mg}$ or $300 \mathrm{mg} .{ }^{14,37}$ Consequently, consistent weight loss is observed with canagliflozin treatment. This effect is desirable in most overweight to obese patients with T2DM and may supplement diet and exercise measures. ${ }^{21}$ The recommended treatment target in patients with excess weight is a weight loss of approximately $5 \%$ for those with body mass index (BMI) $27-35 \mathrm{~kg} / \mathrm{m}^{2}$ or $10 \%$ for those with BMI $>35 \mathrm{~kg} / \mathrm{m}^{2}{ }^{4}$ In the clinical Phase III trials, treatment with canagliflozin $100 \mathrm{mg}$ and $300 \mathrm{mg}$ versus placebo in monotherapy and dual or triple therapy, including combination treatment with insulin, consistently resulted in a statistically significant reduction in body weight. Weight loss was more pronounced with canagliflozin $300 \mathrm{mg}$ than with canagliflozin $100 \mathrm{mg}$ and achieved statistical significance in comparison to placebo, sitagliptin, or glimepiride (Figure 3). ${ }^{14,26-35}$ The head-to-head study versus glimepiride on the background of metformin demonstrated an average weight reduction of $-4.1 \%(-3.6 \mathrm{~kg})$ and $-4.2 \%(-3.6 \mathrm{~kg})$ with canagliflozin $100 \mathrm{mg}$ and $300 \mathrm{mg}$ after 104 weeks compared with a weight gain of approximately $0.9 \%(0.8 \mathrm{~kg})$ with glimepiride. ${ }^{27}$ With canagliflozin $300 \mathrm{mg}$ in combination with metformin and sulfonylurea, the average weight change after 52 weeks was $-2.5 \%(-2.3 \mathrm{~kg})$ compared to triple therapy with sitagliptin, metformin, and sulfonylurea (weight gain of approximately $0.3 \%$ or $0.1 \mathrm{~kg}$ ). ${ }^{32}$ The use of canagliflozin as add-on to insulin ( $\geq 30 \mathrm{IU} / \mathrm{d}$ ) led to average weight reductions of approximately $-2.4 \%(-2.3 \mathrm{~kg})$ and $-3.1 \%(-3.0 \mathrm{~kg})$ after 52 weeks with canagliflozin $100 \mathrm{mg}$ and $300 \mathrm{mg}$, respectively (Figure 3); the mean insulin dose at baseline was $83 \mathrm{IU} / \mathrm{d}$ and did not change over 52 weeks for the majority of patients. ${ }^{38}$

In the 52-week study, weight loss with canagliflozin peaked after approximately 6 months and remained stable until the end of the observation period..$^{28,30,32}$ Investigations to evaluate physical composition, such as dual X-ray absorptiometry and abdominal computed tomography, indicate that nearly two-thirds of the weight loss observed with canagliflozin can be attributed to a loss of body fat, with preferential reductions in visceral versus subcutaneous fat stores. ${ }^{28}$

\section{Concomitant effects on blood pressure}

The majority of patients with T2DM are affected by further comorbidities, which contribute to increased cardiovascular risk. ${ }^{37}$ These comorbidities predominantly include excess weight, lipometabolic disorders, and hypertension. Estimates assume that well over two-thirds of all people with T2DM have high blood pressure. ${ }^{39}$ Together with glycemic control and weight reduction, the reduction of elevated blood pressure is one of the primary treatment targets for patients with T2DM. ${ }^{4}$ Outcome data show that a reduction of systolic blood pressure by 5-6 $\mathrm{mmHg}$ can reduce the long-term risk of cardiovascular morbidity and mortality in this patient group. ${ }^{40}$

Hospital data from Germany have been able to confirm that the most common comorbidity diagnosed in $77.8 \%$ of patients with T2DM was hypertension. ${ }^{41}$ Frequently, no satisfactory blood pressure target is achieved for these patients in practice despite antihypertensive treatment. ${ }^{40}$ The mechanism of action of SGLT2 inhibition with canagliflozin is aimed at a therapeutic 
increase in glucose excretion in the urine. SGLT2 inhibition is thereby associated with mild osmotic diuresis and increased sodium excretion, as well as weight loss. ${ }^{21}$ These mechanisms lead to a reduction in blood pressure at the same time. ${ }^{37}$ A pooled analysis of four randomized, double-blind, Phase III trials with 2,313 patients with T2DM shows that canagliflozin reduced systolic and diastolic blood pressure by an average of $4.7 \mathrm{mmHg}$ and $1.9 \mathrm{mmHg}$ (300 $\mathrm{mg}$ dose) or by $4.0 \mathrm{mmHg}$ and $1.9 \mathrm{mmHg}$ (100 mg dose) compared with placebo. No clinically relevant change in heart rate was observed $(-0.6$ beats $/ \mathrm{min},-0.4$ beats/ $\mathrm{min}$, and 0.0 beats/min with canagliflozin $100 \mathrm{mg}$ and $300 \mathrm{mg}$ and placebo, respectively). ${ }^{42}$

\section{Tolerability and safety of canagliflozin}

The safety of canagliflozin treatment was evaluated for 10,285 patients with T2DM. The primary evaluation was a pooled analysis of placebo-controlled clinical studies. ${ }^{14}$ Specific adverse drug reactions included genital fungal infections, urinary tract infections, adverse events (AEs) associated with mildly increased osmotic diuresis (eg, increased urinary frequency or thirst), and AEs associated with a reduction in intravascular volume (eg, orthostatic hypotension, postural dizziness; Table 2$).{ }^{43}$ These side effects were generally mild to moderate. ${ }^{14}$

Table 2 AEs associated with canagliflozin that occurred in $\geq 2 \%$ of canagliflozin-treated patients

\begin{tabular}{|c|c|c|c|}
\hline \multirow[t]{2}{*}{$\mathbf{A E}$} & \multicolumn{3}{|c|}{ Patients, n (\%) } \\
\hline & $\begin{array}{l}\text { PBO } \\
(n=646)\end{array}$ & $\begin{array}{l}\text { CANA } 100 \mathrm{mg} \\
(\mathrm{n}=833)\end{array}$ & $\begin{array}{l}\text { CANA } 300 \mathrm{mg} \\
(\mathrm{n}=834)\end{array}$ \\
\hline \multicolumn{4}{|l|}{ Gastrointestinal AEs } \\
\hline Constipation & $6(0.9)$ & $15(\mathrm{I} .8)$ & $19(2.3)$ \\
\hline Nausea & $10(1.5)$ & I8 (2.2) & $19(2.3)$ \\
\hline \multicolumn{4}{|c|}{ AEs related to osmotic diuresis } \\
\hline Thirst $^{\mathrm{a}}$ & $\mathrm{I}(0.2)$ & $23(2.8)$ & $19(2.3)$ \\
\hline Increased urination ${ }^{\mathrm{b}}$ & $5(0.8)$ & $44(5.3)$ & $38(4.6)$ \\
\hline Urinary tract infection ${ }^{c}$ & $26(4.0)$ & $49(5.9)$ & $36(4.3)$ \\
\hline \multicolumn{4}{|l|}{ Genital AEs } \\
\hline $\begin{array}{l}\text { Female genital } \\
\text { mycotic infection }\end{array}$ & $10(3.2)$ & $44(10.4)$ & $49(11.4)$ \\
\hline Vulvovaginal pruritus $^{\mathrm{d}}$ & 0 & $7(1.6)$ & $13(3.0)$ \\
\hline $\begin{array}{l}\text { Male genital } \\
\text { mycotic infection }{ }^{f, g}\end{array}$ & $2(0.6)$ & $17(4.2)$ & $15(3.7)$ \\
\hline
\end{tabular}

Notes: ancludes thirst, dry mouth, and polydipsia; bincludes polyuria, pollakiuria, urine output increased, micturition urgency, and nocturia; cincludes urinary tract infection, cystitis, kidney infection, and urosepsis; ${ }^{d}$ percentages based on the number of females in each treatment group (PBO, $n=312$; CANA 100 mg, n=425; CANA $300 \mathrm{mg}, \mathrm{n}=430$ ); eincludes vulvovaginal candidiasis, vulvovaginal mycotic infection, vulvovaginitis, vaginal infection, vulvitis, and genital infection fungal; fpercentages based on the number of males in each treatment group (PBO, n=334; CANA $100 \mathrm{mg}, \mathrm{n}=408$; CANA $300 \mathrm{mg}$, $\mathrm{n}=404$ ); includes balanitis or balanoposthitis, balanitis candida, and genital infection fungal. Adapted from Safety and tolerability of canagliflozin in patients with type 2 diabetes: pooled analysis of phase 3 study results. Usiskin K, Kline I, Fung A, Mayer C, Meininger G. Postgraduate Medicine. 2014;126(3):16-34. Taylor \& Francis. Reprinted by permission of Taylor \& Francis Ltd, http://www.tandfonline.com. ${ }^{43}$ Abbreviations: AE, adverse event; PBO, placebo; CANA, canagliflozin.
Potential positive effects of canagliflozin on the lipid profile include elevated high-density lipoprotein cholesterol and decreased triglycerides. Canagliflozin is also associated with a mild dose-dependent increase in low-density lipoprotein cholesterol levels, which appears to be an SGLT2 inhibitor class effect. ${ }^{23,24}$ These effects may be related to hemoconcentration resulting from the mild osmotic diuretic effects of canagliflozin and/or downstream metabolic effects of increasing urinary glucose excretion (eg, shift in energy substrate utilization affecting hepatic triglyceride levels). ${ }^{44}$ Long-term effects of canagliflozin treatment, including changes in lipids, on cardiovascular safety are being evaluated in the CANVAS trial.

\section{Hypoglycemia}

Canagliflozin reduces elevated serum glucose levels by minimizing glucose reabsorption in the proximal kidney tubules. Studies in patients with T2DM show that canagliflozin $300 \mathrm{mg}$ reduces the $\mathrm{RT}_{\mathrm{G}}$ from a starting level of a maximum of approximately $240 \mathrm{mg} / \mathrm{dL}(13.3 \mathrm{mmol} / \mathrm{L})$ to approximately $70-90 \mathrm{mg} / \mathrm{dL}(3.9-5.0 \mathrm{mmol} / \mathrm{L}) .{ }^{45}$ As this level is generally above the threshold for hypoglycemia, canagliflozin bears a low intrinsic risk of hypoglycemia. The clinical trial results confirm this notion: in monotherapy over 52 weeks, similar hypoglycemia rates were observed with canagliflozin $100 \mathrm{mg}$ (5.1\%), canagliflozin $300 \mathrm{mg}$ (3.6\%), and the control group (patients received placebo [weeks 1-26] or sitagliptin [weeks 27-52]; 3.6\%). ${ }^{33}$ Also, in combination with metformin, there was a comparatively low incidence of hypoglycemia; in direct comparison with the sulfonylurea glimepiride, the proportion of patients with hypoglycemia remained consistently low over 104 weeks with canagliflozin (glimepiride, $40.9 \%$; canagliflozin $100 \mathrm{mg}$, $6.8 \%$; canagliflozin $300 \mathrm{mg}, 8.2 \%$ ). This was also true for episodes of severe hypoglycemia (glimepiride, $3.3 \%$; canagliflozin $100 \mathrm{mg}, 0.6 \%$; canagliflozin $300 \mathrm{mg}$, $0.2 \%) .{ }^{27}$ As insulin and insulin secretagogue (eg, sulfonylurea) treatment is the main driver for hypoglycemia in combination therapy, a lower dose of insulin or the insulin secretagogue may be necessary in comedication with canagliflozin. ${ }^{14}$

\section{AEs in conjunction with volume reduction}

SGLT2 inhibition leads to fluid and sodium loss. These effects are caused by glucose-induced osmotic diuresis and the fact that the SGLT2 also functions as a sodium transporter. Based on these mechanisms of action of SGLT2 inhibition, AEs associated with volume depletion need close attention. In clinical studies with canagliflozin, a small increase of clinical signs related to volume deficiency, such as postural dizziness 
and orthostatic hypertension, were seen with the $300 \mathrm{mg}$ dose, especially with concomitant use of loop diuretics. Among patients on loop diuretics, the incidence of volume depletion-related AEs with canagliflozin $100 \mathrm{mg}$ and $300 \mathrm{mg}$ and noncanagliflozin was $3.2 \%, 8.8 \%$, and $4.7 \% .{ }^{14}$ These side effects predominantly occurred in the first 3 months, after which the incidence declined. ${ }^{46}$

\section{Urinary tract infections and genital mycotic infections}

T2DM is associated with increased incidence of urinary tract infections and genital mycotic infections in both men and women. This is, in part, attributed to a reduced mucosa-associated immune defense exerted by chronic hyperglycemia. ${ }^{47}$ Treatment with an SGLT2 inhibitor, such as canagliflozin, reduces the glucose reabsorption in the kidneys. As a result, increased concentrations of glucose are excreted in the urine, and thereby blood glucose levels are reduced. The glucosuria associated with this mechanism of action may, at least potentially, favor the growth of uropathogenic bacteria. ${ }^{48,49}$

In clinical trials, patients experienced more urinary tract infections with canagliflozin treatment than in the control groups, regardless of the dose. In the pooled placebocontrolled studies, the incidence of urinary tract infections with canagliflozin $100 \mathrm{mg}$ and $300 \mathrm{mg}$ and placebo was $5.9 \%, 4.3 \%$, and $4.0 \%$, respectively (Table 2 ); the incidence of urinary tract infections was $0.5 \%, 2.2 \%$, and $0.6 \%$, respectively, in males, and $11.1 \%, 6.3 \%$, and $7.7 \%$, respectively, in females. ${ }^{48}$ These infections were generally mild to moderate, and only a few patients developed more than one episode of symptomatic urinary tract infection. Common symptoms included dysuria, frequent urination, urinary urgency, and/or suprapubic discomfort. The duration of symptoms was comparable with canagliflozin and placebo ( 11-12 days). There were no indications that canagliflozin increased the incidence of recurring infections. In general, urinary tract infections responded well to standard treatment without the need for discontinuation of canagliflozin. ${ }^{48}$

A higher rate of genital mycotic infections was observed in clinical trials with canagliflozin treatment in both men and women, regardless of the dose (Table 2). ${ }^{43,49}$ In the pooled placebo-controlled studies, the incidence of genital mycotic infections with canagliflozin $100 \mathrm{mg}$ and $300 \mathrm{mg}$ and placebo was $4.2 \%, 3.7 \%$, and $0.6 \%$, respectively, in males, and $10.4 \%$, $11.4 \%$, and $3.2 \%$, respectively, in females. ${ }^{43}$ Infections were generally mild to moderate, responded to standard treatment (topical in the majority of cases), and only rarely led to discontinuation of the study medication, canagliflozin. Most genital fungal infections were confirmed by clinical diagnosis, without the necessity of further diagnostic evaluation. Many patients treated the infection by themselves. The majority of genital fungal infections were treated with antimycotics (topical and/or rarely oral) without discontinuation of canagliflozin. ${ }^{49}$

Overall, genital fungal infections occurred more commonly in women than in men, and mainly during the first 4 months of treatment with canagliflozin. Thereafter, the incidence was minor. ${ }^{49}$ Diabetes is a predisposing factor for vulvovaginal candidiasis in women. Glucosuria promotes the attachment and growth of yeast to the vaginal mucosa. Women who developed a genital fungal infection under treatment with canagliflozin were generally younger, had a higher BMI, were more commonly premenopausal, and more frequently reported a previous history of vulvovaginitis. No differences in baseline $\mathrm{HbA}_{1 \mathrm{c}}$ or diabetes duration were observed between women with and without genital mycotic infections with canagliflozin treatment. ${ }^{49}$

In the male group, the incidence of genital fungal infections (eg, balanitis, balanoposthitis) overall was low. Mostly, the infections occurred during the first year of treatment. Those affected more commonly had diabetes for a longer duration, and had a previous history of balanitis/balanoposthitis compared to men without this AE. Genital mycotic infections were less frequently observed in circumcised men. ${ }^{49}$

\section{Use of SGLT2 inhibition in everyday practice}

The oral antidiabetic canagliflozin is available in $100 \mathrm{mg}$ and $300 \mathrm{mg}$ doses. It is licensed for use in the treatment of T2DM, in conjunction with diet and exercise, in the following regimens ${ }^{14}$ :

- Monotherapy, if use of metformin is considered unsuitable due to intolerability or contraindications

- Combination therapy with other oral antidiabetics, dual combination or triple combination

- Combination therapy with insulin, with or without other oral antidiabetics

When planning treatment with an SGLT2 inhibitor, one may consider the following aspects of treatment with the SGLT2 inhibitor canagliflozin:

- Works independently of insulin (ie, independently of endogenous beta-cell function and/or insulin action)

- Is not associated with an intrinsic risk of hypoglycemia

- Can be combined with other oral antidiabetics and insulin (in combination therapy with insulin or an insulin 
Table 3 Measures against possible side effects of SGLT2 inhibition with canagliflozin in specific patient populations ${ }^{14}$

\begin{tabular}{|c|c|c|}
\hline Patient subgroup & Possible AEs with SGLT2 inhibition & Measures \\
\hline Women with a history & Increased risk of recurring genital & Sufficient patient information \\
\hline of vaginal fungal infection & fungal infections & Treatment with oral or topical antimycotics \\
\hline Elderly patients (age $\geq 65$ years) & $\begin{array}{l}\text { Events in conjunction with volume reduction } \\
\text { (eg, orthostatic hypotension, postural dizziness) }\end{array}$ & $\begin{array}{l}\text { Ensure adequate patient hydration } \\
\text { (drink sufficiently) }\end{array}$ \\
\hline $\begin{array}{l}\text { Chronic kidney disease (eGFR of } \\
45 \text { to }<60 \mathrm{~mL} / \mathrm{min} / 1.73 \mathrm{~m}^{2} \text { ) }\end{array}$ & $\begin{array}{l}\text { Events in conjunction with volume reduction } \\
\text { (eg, orthostatic hypotension, postural dizziness), } \\
\text { raised potassium levels, raised urea }\end{array}$ & $\begin{array}{l}\text { Restrict canagliflozin dose to } 100 \mathrm{mg} \text { daily }(300 \mathrm{mg} \\
\text { dose should not be used where eGFR }<60 \mathrm{~mL} / \mathrm{min} / \\
\left.1.73 \mathrm{~m}^{2}\right)\end{array}$ \\
\hline & & $\begin{array}{l}\text { Close monitoring of kidney levels and potassium serum } \\
\text { No treatment with canagliflozin when eGFR }<45 \mathrm{~mL} \\
\mathrm{~min} / 1.73 \mathrm{~m}^{2}\end{array}$ \\
\hline $\begin{array}{l}\text { Patients with insulin } \\
\text { or sulfonylurea }\end{array}$ & $\begin{array}{l}\text { Hypoglycemia (no intrinsic risk of } \\
\text { hypoglycemia under canagliflozin) }\end{array}$ & Consider a reduction on dose of insulin or sulfonylurea \\
\hline Patients with diuretics & $\begin{array}{l}\text { Events in conjunction with volume } \\
\text { reduction (eg, orthostatic hypotension, } \\
\text { postural dizziness) }\end{array}$ & $\begin{array}{l}\text { Ensure suitable patient hydration (drink sufficiently) } \\
\text { Canagliflozin is not recommended in patients receiving } \\
\text { loop diuretics }\end{array}$ \\
\hline
\end{tabular}

Notes: Adapted from Mikhail N. Safety of canagliflozin in patients with type 2 diabetes. Curr Drug Saf. 2014;9(2):127-132. Reprinted by permission of Eureka Science Ltd. Copyright @ 2014 Bentham Science Publishers. ${ }^{50}$

Abbreviations: SGLT2, sodium glucose cotransporter 2; AE, adverse event; eGFR, estimated glomerular filtration rate.

secretagogue, dose reduction may be necessary under certain circumstances in order to avoid hypoglycemia) in any phase of diabetes history

- Has been demonstrated, in the $300 \mathrm{mg}$ dose as add-on to metformin, to exert superior $\mathrm{HbA}_{1 \mathrm{c}}$ reduction compared with sitagliptin or glimepiride

- Is associated with beneficial concomitant actions, such as weight reduction (significant differences in direct comparison with sitagliptin or glimepiride) and blood pressure reduction, in addition to glycemic control.

Overall, canagliflozin is well tolerated. Specifically, however, in everyday practice, the increased incidence of genital mycotic infections and urinary tract infections should be taken into account (Table 3). ${ }^{14,50}$ Additionally, clinicians should monitor patients' lipid profiles per standard of care. An extensive, long-term outcome study program with canagliflozin (CANVAS) is currently being performed, ${ }^{25}$ from which outcomes on the effects on macrovascular and microvascular endpoints are expected in the next few years.

\section{Summary}

SGLT2 inhibition with canagliflozin leads to therapeutic glucosuria in patients with T2DM. This mechanism is independent of beta-cell mass, insulin secretion, and/or insulin sensitivity. An extensive, clinical Phase III trial program with 10,285 patients confirmed the consistent antihyperglycemic efficacy of the SGLT2 inhibitor canagliflozin. Weight reduction and moderate blood pressure reduction were observed as favorable concomitant effects of blood sugar control under canagliflozin. A long-term outcome study program (including CANVAS and CANVAS-R studies) is currently testing the impact of canagliflozin on macrovascular and renal endpoints. In everyday practice, a higher incidence of genital mycotic infections and urinary tract infections needs to be taken into account with SGLT2 inhibitors, especially in women. Owing to the insulin-independent mechanism of action, the therapeutic use of canagliflozin is possible in any phase of diabetes history.

\section{Acknowledgments}

Editorial support was provided by Kimberly Dittmar, $\mathrm{PhD}$, of MedErgy, and was funded by Janssen Pharmaceutica NV. The author retained full editorial control over the content of the article.

Canagliflozin has been developed by Janssen Research \& Development, LLC, in collaboration with Mitsubishi Tanabe Pharma Corporation.

\section{Disclosure}

JS has received honoraria for speaker boards and advisory boards, and/or research support from Takeda, Bayer, Novartis, Merck Sharp \& Dohme, AstraZeneca, Bristol-Myers Squibb, Novo Nordisk, Sanofi Aventis, Berlin Chemie, Eli Lilly, Boehringer Ingelheim, Merck, Roche, Ipsen, Pfizer, Janssen, LifeScan, OmniaMed, Intarcia, Lexicon, and Apitope. The author reports no other conflicts of interest in this work.

\section{References}

1. Inzucchi SE, Bergenstal RM, Buse JB, et al. Management of hyperglycemia in type 2 diabetes, 2015: a patient-centered approach: update to a position statement of the American Diabetes Association and the European Association for the Study of Diabetes. Diabetes Care. 2015;38(1):140-149. 
2. de Pablos-Velasco P, Parhofer KG, Bradley C, et al. Current level of glycaemic control and its associated factors in patients with type 2 diabetes across Europe: data from the PANORAMA study. Clin Endocrinol (Oxf). 2014;80(1):47-56.

3. Fonseca VA. Defining and characterizing the progression of type 2 diabetes. Diabetes Care. 2009;32(Suppl 2):S151-S156.

4. Bundesärztekammer (B̈̈K), Kassenärztliche Bundesvereinigung (KBV), Arbeitsgemeinschaft der Wissenschaftlichen Medizinischen Fachgesellschaften $(A W M F)$. Nationale VersorgungsLeitlinie Therapie des Typ-2Diabetes - Langfassung, 1. Auflage. Version 3. 2013, zuletzt geändert: April 2014. [National Patient-Centered Guideline: Therapy of Type 2 Diabetes - Long Version, 1. Edition, Version 3. 2013, latest adaptation: April 2014]. DOI: 10.6101/AZQ/000203. Available from: http://www. versorgungsleitlinien.de/themen/diabetes $2 / \mathrm{dm} 2$ _therapie. Accessed November 19, 2014. German.

5. Sarwar N, Gao P, Seshasai SR, et al. Diabetes mellitus, fasting blood glucose concentration, and risk of vascular disease: a collaborative meta-analysis of 102 prospective studies. Lancet. 2010;375(9733): 2215-2222.

6. Hauner H, Hanisch J, Bramlage P, et al. Prevalence of undiagnosed type-2-diabetes mellitus and impaired fasting glucose in German primary care: data from the German Metabolic and Cardiovascular Risk Project (GEMCAS). Exp Clin Endocrinol Diabetes. 2008;116(1): $18-25$.

7. Berthold HK, Gouni-Berthold I, Bestehorn K, et al. Kardiovaskuläre Risikofaktoren bei Typ-2-Diabetikern in Deutschland - ein Versorgungsparadox. [Cardiovascular Risk Factors in Patients With Type 2 Diabetes in Germany]. Dtsch Arztebl. 2007;104(A):861-867. German.

8. UK Prospective Diabetes Study (UKPDS) Group. Effect of intensive blood-glucose control with metformin on complications in overweight patients with type 2 diabetes (UKPDS 34). Lancet. 1998;352(9131): 854-865.

9. Dormandy JA, Charbonnel B, Eckland DJ, et al. Secondary prevention of macrovascular events in patients with type 2 diabetes in the PROactive Study (PROspective pioglitAzone Clinical Trial In macroVascular Events): a randomised controlled trial. Lancet. 2005; 366(9493):1279-1289.

10. Scirica BM, Bhatt DL, Braunwald E, et al. Saxagliptin and cardiovascular outcomes in patients with type 2 diabetes mellitus. $N$ Engl $J$ Med. 2013;369(14):1317-1326.

11. White WB, Cannon CP, Heller SR, et al. Alogliptin after acute coronary syndrome in patients with type 2 diabetes. $N$ Engl J Med. 2013;369(14): 1327-1335.

12. Bays H. From victim to ally: the kidney as an emerging target for the treatment of diabetes mellitus. Curr Med Res Opin. 2009;25(3): 671-681.

13. Rahmoune H, Thompson PW, Ward JM, Smith CD, Hong G, Brown J. Glucose transporters in human renal proximal tubular cells isolated from the urine of patients with non-insulin-dependent diabetes. Diabetes. 2005;54(12):3427-3434

14. INVOKANA ${ }^{\mathrm{TM}}$ (canagliflozin) tablets, for oral use [summary of product characteristics]. Beerse, Belgium: Janssen-Cilag International NV; 2015.

15. Sha S, Polidori D, Farrell K, et al. Pharmacodynamic differences between canagliflozin and dapagliflozin: results of a randomized, double-blind, crossover study. Diabetes Obes Metab. 2015;17(2):188-197.

16. Polidori D, Sha S, Mudaliar S, et al. Canagliflozin lowers postprandial glucose and insulin by delaying intestinal glucose absorption in addition to increasing urinary glucose excretion: results of a randomized, placebo-controlled study. Diabetes Care. 2013;36(8):2154-2161.

17. Ferrannini E, Muscelli E, Frascerra S, et al. Metabolic response to sodium-glucose cotransporter 2 inhibition in type 2 diabetic patients. J Clin Invest. 2014;124(2):499-508.

18. Liang Y, Arakawa K, Ueta K, et al. Effect of canagliflozin on renal threshold for glucose, glycemia, and body weight in normal and diabetic animal models. PLoS One. 2012;7(2):e30555.
19. Sha S, Devineni D, Ghosh A, et al. Canagliflozin, a novel inhibitor of sodium glucose co-transporter 2 , dose dependently reduces calculated renal threshold for glucose excretion and increases urinary glucose excretion in healthy subjects. Diabetes Obes Metab. 2011;13(7): 669-672.

20. Nomura S, Sakamaki S, Hongu M, et al. Discovery of canagliflozin, a novel C-glucoside with thiophene ring, as sodium-dependent glucose cotransporter 2 inhibitor for the treatment of type 2 diabetes mellitus. J Med Chem. 2010;53(17):6355-6360.

21. Seufert J. SGLT-2 inhibition with canagliflozin: a new option for the treatment of type 2 diabetes. Dtsch Med Wochenschr. 2014; 139(Suppl 2):S52-S58.

22. Ehrenkranz JR, Lewis NG, Kahn CR, Roth J. Phlorizin: a review. Diabetes Metab Res Rev. 2005;21(1):31-38.

23. FORXIGA ${ }^{\mathrm{TM}}$ (dapagliflozin) $5 \mathrm{mg}$ and $10 \mathrm{mg}$ film-coated tablets [summary of product characteristics]. Middlesex, UK: Bristol-Myers Squibb/AstraZeneca EEIG; 2014.

24. JARDIANCETM (empagliflozin) $10 \mathrm{mg}$ film-coated tablets [summary of product characteristics]. Ingelheim, Germany: Boehringer Ingelheim $\mathrm{GmbH} ; 2014$.

25. Neal B, Perkovic V, de Zeeuw D, et al. Rationale, design, and baseline characteristics of the canagliflozin cardiovascular assessment study (CANVAS) - a randomized placebo-controlled trial. Am Heart $J$. 2013;166(2):217-223.

26. Bode B, Stenlöf K, Sullivan D, Fung A, Usiskin K. Efficacy and safety of canagliflozin treatment in older subjects with type 2 diabetes mellitus: a randomized trial. Hosp Pract (1995). 2013;41(2):72-84.

27. Leiter LA, Yoon KH, Arias P, et al. Canagliflozin provides durable glycemic improvements and body weight reduction over 104 weeks versus glimepiride in patients with type 2 diabetes on metformin: a randomized, double-blind, Phase 3 study. Diabetes Care. 2015;38(3): 355-364.

28. Cefalu WT, Leiter LA, Yoon KH, et al. Efficacy and safety of canagliflozin versus glimepiride in patients with type 2 diabetes inadequately controlled with metformin (CANTATA-SU): 52 week results from a randomised, double-blind, phase 3 non-inferiority trial. Lancet. 2013;382(9896):941-950.

29. Forst T, Guthrie R, Goldenberg R, et al. Efficacy and safety of canagliflozin over 52 weeks in patients with type 2 diabetes on background metformin and pioglitazone. Diabetes Obes Metab. 2014;16(5): $467-477$.

30. Lavalle-González FJ, Januszewicz A, Davidson J, et al. Efficacy and safety of canagliflozin compared with placebo and sitagliptin in patients with type 2 diabetes on background metformin monotherapy: a randomised trial. Diabetologia. 2013;56(12):2582-2592.

31. Neal B, Perkovic V, de Zeeuw D, et al. Efficacy and safety of canagliflozin, an inhibitor of sodium glucose co-transporter 2, when used in conjunction with insulin therapy in patients with type 2 diabetes. Diabetes Care. 2015;38(3):403-411.

32. Schernthaner G, Gross JL, Rosenstock J, et al. Canagliflozin compared with sitagliptin for patients with type 2 diabetes who do not have adequate glycemic control with metformin plus sulfonylurea: a 52-week, randomized trial. Diabetes Care. 2013;36(9):2508-2515.

33. Stenlöf K, Cefalu WT, Kim KA, et al. Long-term efficacy and safety of canagliflozin monotherapy in patients with type 2 diabetes inadequately controlled with diet and exercise: findings from the 52-week CANTATA-M study. Curr Med Res Opin. 2014;30(2):163-175.

34. Stenlöf K, Cefalu WT, Kim KA, et al. Efficacy and safety of canagliflozin monotherapy in subjects with type 2 diabetes mellitus inadequately controlled with diet and exercise. Diabetes Obes Metab. 2013;15(4):372-382.

35. Bode B, Stenlöf K, Harris S, et al. Long-term efficacy and safety of canagliflozin over 104 weeks in patients aged 55 to 80 years with type 2 diabetes. Diabetes Obes Metab. 2015;17(3):294-303.

36. Gilbert RE, Weir MR, Fioretto P, Law G, Usiskin K, Meninger G. Effect of canagliflozin (CANA) in patients with type 2 diabetes mellitus (T2DM) based on age and estimated glomerular filtration rate (eGFR) [abstract]. Diabetes. 2014;(Suppl 1):A212-A343. Abstract 1034-P. 
37. Basile JN. The potential of sodium glucose cotransporter 2 (SGLT2) inhibitors to reduce cardiovascular risk in patients with type 2 diabetes (T2DM). J Diabetes Complications. 2013;27(3):280-286.

38. Neal B, Matthews D, Fulcher G, et al. 52-week effects of canagliflozin, an inhibitor of sodium glucose co-transporter 2 (SGLT2), added to insulin therapy in type 2 diabetes (T2D). Poster presented at: $22 \mathrm{nd}$ Biennial World Diabetes Congress of the International Diabetes Federation (IDF); December 2-6, 2013; Melbourne, Australia.

39. Ferrannini E, Cushman WC. Diabetes and hypertension: the bad companions. Lancet. 2012;380(9841):601-610.

40. Matthaei S. Canagliflozin monotherapy: clinical study data in type 2 diabetes mellitus. Dtsch Med Wochenschr. 2014;139(Suppl 2): S59-S64.

41. Wilke T, Ahrendt P, Schwartz D, Linder R, Ahrens S, Verheyen F. Incidence and prevalence of type 2 diabetes mellitus in Germany: an analysis based on 5.43 million patients. Dtsch Med Wochenschr. 2013; 138(3):69-75.

42. Weir M, Januszewicz A, Gilbert R, et al. Effect of canagliflozin on blood pressure and adverse events related to osmotic diuresis and reduced intravascular volume in patients with type 2 diabetes mellitus. J Clin Hypertens (Greenwich). 2014;16(12):875-882.

43. Usiskin K, Kline I, Fung A, Mayer C, Meininger G. Safety and tolerability of canagliflozin in patients with type 2 diabetes: pooled analysis of phase 3 study results. Postgrad Med. 2014;126(3):16-34.
44. Weidmann P, de Courten M, Ferrari P. Effect of diuretics on the plasma lipid profile. Eur Heart J. 1992;13(Suppl G):61-67.

45. Plosker GL. Canagliflozin: a review of its use in patients with type 2 diabetes mellitus. Drugs. 2014;74(7):807-824.

46. Committee for Medicinal Products for Human Use (CHMP). Assessment Report Canagliflozin. EMA/374133/2013; September 19, 2013. Available from: http://www.ema.europa.eu/docs/en_GB/document_library/ EPAR_-_Public_assessment_report/human/002649/WC500156457. pdf. Accessed November 19, 2014.

47. Amir J, Waite M, Tobler J, et al. The role of hyperglycemia in mechanisms of exacerbated inflammatory responses within the oral cavity. Cell Immunol. 2011;272(1):45-52.

48. Nicolle LE, Capuano G, Fung A, Usiskin K. Urinary tract infection in randomized phase III studies of canagliflozin, a sodium glucose co-transporter 2 inhibitor. Postgrad Med. 2014;126(1):7-17.

49. Nyirjesy P, Sobel JD, Fung A, et al. Genital mycotic infections with canagliflozin, a sodium glucose co-transporter 2 inhibitor, in patients with type 2 diabetes mellitus: a pooled analysis of clinical studies. Curr Med Res Opin. 2014;30(6):1109-1119.

50. Mikhail N. Safety of canagliflozin in patients with type 2 diabetes. Curr Drug Saf. 2014;9(2):127-132.

\section{Publish your work in this journal}

Diabetes, Metabolic Syndrome and Obesity: Targets and Therapy is an international, peer-reviewed open-access journal committed to the rapid publication of the latest laboratory and clinical findings in the fields of diabetes, metabolic syndrome and obesity research. Original research, review, case reports, hypothesis formation, expert opinion and commentaries are all considered for publication. The manuscript management system is completely online and includes a very quick and fair peer-review system, which is all easy to use. Visit http://www.dovepress.com/testimonials.php to read real quotes from published authors. 